\title{
Electronic cigarette use in Greece: an analysis of a representative population sample in Attica prefecture
}

\author{
Konstantinos E. Farsalinos ${ }^{1,2,3^{*}}$ (D), Georgios Siakas ${ }^{4}$, Konstantinos Poulas ${ }^{2}$, Vassilis Voudris ${ }^{1}$, Kyriakoula Merakou ${ }^{3}$ \\ and Anastasia Barbouni ${ }^{3}$
}

\begin{abstract}
Background: The purpose was to assess prevalence and correlates of electronic cigarette (e-cigarette) use in Greece in 2017.

Methods: A cross-sectional survey of a representative sample of 4058 adults living in Attica prefecture (35\% of the Greek adult population) was performed in May 2017 through telephone interviews. Prevalence and frequency of e-cigarette use were assessed according to the smoking status, and logistic regression analysis was performed to identify correlates of use.

Results: Current smoking was reported by $32.6 \%$ of participants. Ever e-cigarette use was reported by $54.1 \%$ (51.4-56.8\%) of current smokers, $24.1 \%$ (21.7-26.5\%) of former smokers and 6.5\% (5.3-7.7\%) of never smokers. Past experimentation was the most prevalent pattern of e-cigarette use among ever users ( $P<0.001)$. Almost $80 \%$ of ever and $90 \%$ of current e-cigarette users were using nicotine. Extrapolated to the whole Attica population (3.1 million), there were 1 million current smokers, 848,000 ever e-cigarette users and 155,000 current e-cigarette users. The majority of current e-cigarette users (62.2\%) were former smokers. Only $0.2 \%$ of never smokers were current e-cigarette users. One out of 20 participants considered e-cigarettes a lot less harmful than smoking. Being current or former smoker were the strongest correlates current e-cigarette use (OR 30.82, 95\% Cl 10. 21-69.33 and OR 69.33, 95\% 23.12-207.90 respectively).

Conclusions: E-cigarette use in Greece is largely confined to current or former smokers, while current use and nicotine use by never smokers is extremely rare. The majority of current e-cigarette users were former smokers. Most participants overestimate the harmfulness of e-cigarettes relative to smoking.
\end{abstract}

Keywords: Electronic cigarettes, Smoking/harm reduction, Nicotine, Greece

\section{Background}

Electronic cigarettes (e-cigarettes) have been increasingly popular over the past few years, and this has been a matter of intense debate within the public health community. Two major areas of concern are their safety/risk profile and patterns of use by the population. For the former, currently available evidence suggests that they are by far less harmful than smoking; however, these estimates are mainly derived from chemistry and toxicology studies, and there is still no long-term epidemiological evidence to accurately quantify the level of risk reduction [1-4]. Moreover, e-cigarettes emit

\footnotetext{
*Correspondence: kfarsalinos@gmail.com

${ }^{1}$ Onassis Cardiac Surgery Center, Sygrou 356, 17674 Kallithea, Greece

2Department of Pharmacy, University of Patras, 26500 Rio, Greece

Full list of author information is available at the end of the article
}

some toxins, although at low levels, suggesting that they are not absolutely safe. The use and popularity of e-cigarettes among various population subgroups can raise important issues. From a public health perspective, e-cigarette use would be desirable if it was confined to smokers and if the intended use would be as substitute for smoking. Additionally, it is important to assess whether e-cigarette use promotes smoking cessation. On the contrary, use by non-smokers would result in exposure to toxins which could confer some additional health risk compared to not using any inhalational product. Therefore, assessing the patterns of e-cigarette use in the population, focusing on the smoking status of users, is particularly important in determining the public health impact of e-cigarettes [3].

(C) The Author(s). 2018 Open Access This article is distributed under the terms of the Creative Commons Attribution 4.0 International License (http://creativecommons.org/licenses/by/4.0/), which permits unrestricted use, distribution, and reproduction in any medium, provided you give appropriate credit to the original author(s) and the source, provide a link to the Creative Commons license, and indicate if changes were made. The Creative Commons Public Domain Dedication waiver (http://creativecommons.org/publicdomain/zero/1.0/) applies to the data made available in this article, unless otherwise stated. 
Few randomized controlled trials assessing the efficacy of e-cigarettes in smoking cessation and reduction have shown modest results [5-7]. A metanalysis of such studies has shown that e-cigarettes are effective in smoking cessation, but the level of evidence was low [8]. Several cohort studies have shown mixed results [9-12], which was also reflected in metanalyses showing that e-cigarettes promote, have no effect or prevent smoking cessation [1315]. Several concerns have been raised about these studies, mainly methodological issues that create substantial bias and make many of the studies unsuitable for evaluating the effects of e-cigarettes on smoking cessation [16]. A review of studies evaluating e-cigarettes effects on smoking cessation identified that only a small proportion met the proposed quality criteria [16]. Additionally, randomized controlled trials have inherent problems, such as the long duration for trial planning, recruitment, implementation and analysis [17]. Thus, they may not be the best way of assessing a behavioural intervention such as e-cigarette use, with the large variability of devices and flavours being used according to self-preference by consumers. In this context, real world and population studies provide a useful insight on the impact of e-cigarettes on smoking prevalence. In the UK, the increase in prevalence of e-cigarette use by smokers was positively associated with the success rates of quit attempts and the association remained significant after adjustment for a range of confounding variables [18]. In their latest report, Public Health England (PHE) estimated that e-cigarettes have contributed up to 57,000 additional former smokers in 2016 in the UK [19].

Greece historically has a high prevalence of smoking, ranked among the highest within the European Union [20]. In 2002, the prevalence of smoking was $39.2 \%$ in the EU and 42\% in Greece [21]. By 2014, the smoking prevalence was reduced to $26 \%$ in the EU (a 34\% relative reduction) but remained quite high in Greece (38\%, a $10 \%$ relative reduction) [20]. While e-cigarettes appear to have become popular in Greece, no published studies have provided any data on the true prevalence of e-cigarette use and the patterns of use by different population subgroups. For this reason, a cross-sectional study was performed in 2017, evaluating smoking and e-cigarette use in adult inhabitants of the Attica prefecture, the largest prefecture of Greece. The main aims of this study were to assess the (1) e-cigarette awareness and prevalence of ever, current and past e-cigarette use, as well as past experimentation; (2) prevalence of nicotine-containing e-cigarette use; and (3) correlates of ever and current e-cigarette use.

\section{Methods}

\section{Design, setting and participants}

The cross-sectional study was performed in May 2017 in a sample of 4058 respondents aged $\geq 18$ years. The population of the survey was inhabitants in the Attica prefecture.
This region hosts $35 \%$ of the total adult population of Greece according to Census 2011 (http://www.statistics. gr/en/2011-census-pop-hous) and consists of the Regional Departments of Athens, Piraeus, Eastern Attica and Western Attica. The sample drawn was representative of the prefecture of Attica population, with all registered landline phone numbers being used as the sampling frame. According to the Hellenic Authority for Telecommunications and Postal services (www.eett.gr) landline phones penetration in 2016 was $44.1 \%$ of the population, while mobile phones was $148 \%$. The above difference is a common example for a possible coverage error [22]. For the landline phones, the potential issue on the survey is the under-coverage, but for the usage of mobiles phones, it is the over-coverage. Unfortunately, there is no reliable benchmark study for the Greek population that identifies the direction, strength and potential implications of the coverage error. Using the landline phones prevented the error of over-presenting into the sample people that own more than one mobile phone. The mode of data collection was computer-assisted telephone interviews (CATI), and the sample design was stratified random sampling. Further post-survey adjustment weights were applied in order to depict sample composition as the actual population demographics.

The study was approved by the ethics committee of the Onassis Cardiac Surgery Center (reference no. 591/14.12. 16). All participants provided verbal consent at the beginning of the interview in order to participate to this study.

\section{Sociodemographic factors}

The exact age of the participants was recorded and then recoded into five categories $(18-24,25-39,40-54$ and 55 years and older). Education was coded as "high school or less", "technical education", "university education" and "postgraduate education". Marital status was recorded and categorized as "single", "married/living with a partner" and "widowed/divorced". The financial status of the participants was assessed through a question seeking a self-assessment report of the financial conditions of each household: "How would you characterize your financial situation?”. Response options were "We are unable to cope with our household finances" (very bad financial situation), "We are able to cope with our household finances, but with a lot of difficulties" (bad financial situation), "We are able to to cope with our household finances, but without the ability to save a lot of money" (not good financial situation), and "We don't have financial problems" (good financial situation). This variable attempts to accommodate measurement issues, processing errors and item nonresponse errors [22, 23]. For the analysis, responses were recoded into three groups ("very bad/bad", "not good", and "good"). 


\section{Smoking and e-cigarette use}

Participants were categorized according to their smoking status as current smokers, past smokers and never smokers. Current and former smokers were asked whether they were smoking daily or occasionally. Current daily smokers were asked whether they had tried to quit smoking in the past 3 years and, if yes, which smoking cessation methods they had used. Response options were "Nicotine replacement therapies", "Oral smoking cessation medications", "Psychological support", "E-cigarettes" and "By myself (without any aid) ", with participants being able to choose multiple responses.

E-cigarette awareness was assessed by asking: "Have you ever heard of e-cigarettes?". Those responding "No" were classified as never e-cigarette users and no further questions about e-cigarettes were asked. E-cigarette use was assessed by asking: "Regarding the use of ecigarettes, which of the following statements applies to you?" The responses "I currently use e-cigarettes" (current use), "I used them in the past, but no longer use them" (past use) and "I tried them in the past only once or twice" (past experimentation) were categorized as ever e-cigarette use. The response "I have never used them" was categorized as never use. A separate question assessed the use of nicotine-containing e-cigarettes among ever e-cigarette users, by asking "Do/did you use nicotine in your e-cigarette?" Current and past ecigarette users were asked whether they use or used the e-cigarette daily or occasionally. The harm perception for e-cigarettes was examined by asking "Do you think e-cigarettes are...", with available responses being "A lot more harmful than tobacco cigarettes", "More harmful than tobacco cigarettes", "As harmful as tobacco cigarettes", "Less harmful than tobacco cigarettes", "A lot less harmful than tobacco cigarettes", "Absolutely harmless" and "Don't know".

\section{Statistical analysis}

All values were presented as weighted proportions with $95 \% \mathrm{CI}$, while the projected number within the Attica population was extrapolated based on the total sampling population using an appropriate weighing variable. Differences in prevalence of e-cigarette current use, past use and past experimentation were assessed using chisquare $\left(\chi^{2}\right)$ test. Two separate logistic regression analyses were performed to assess correlates of ever and current e-cigarette use, similarly to a previous analysis of data from Eurobarometer 2014 [24]. Independent variables included all demographics as well as the perception of e-cigarette harmfulness. The latter was recoded as a binary variable, with responses "A lot more harmful than tobacco cigarettes", "More harmful than tobacco cigarettes", "As harmful as tobacco cigarettes" and
"Don't know" coded as 1 and "Less harmful than tobacco cigarettes", "A lot less harmful than tobacco cigarettes" and "Absolutely harmless" coded as 2 . All analyses were weighted and were performed with commercially available software (SPSS v.22.0, Chicago, IL, USA).

\section{Results}

Smoking and e-cigarette use in the population of Attica Participant demographics are presented in Additional file 1: Table S1. The prevalence of smoking and e-cigarette use is shown in Table 1. Current smoking was reported by $32.6 \%$ of the population while an additional $29.7 \%$ were former smokers. The majority were daily smokers $(85.8 \%$ for current smokers and $76.9 \%$ for former smokers). Cessation attempts over the past 3 years were reported by $46.9 \%$ (95\%CI $44.0-49.8 \%$ ) of current daily smokers. Among these, quitting without any aid was the most popular method $(74.6 \%, 95 \% \mathrm{CI}$ $70.9-78.3 \%)$, followed by e-cigarettes $(47.4 \%, 95 \% \mathrm{CI}$ 43.1-51.6\%), nicotine replacement therapies (13.0\%, 95\%CI 10.1-15.8\%) and oral smoking cessation medications $(4.9 \%, 95 \%$ CI 3.1-6.7\%). Extrapolated to the total Attica population, there were 194,000 current daily smokers who had used e-cigarettes in a smoking cessation attempt compared to 53,000 using nicotine replacement therapies and 20,000 using oral smoking cessation medications.

More than 9 out of 10 participants were aware of ecigarettes. Ever e-cigarette use was reported by $27.2 \%$ of the population. Current e-cigarette use was reported by $5.0 \%$ of the population, while 1 out of 10 participants reported being past e-cigarette users. The majority were daily e-cigarette users (78.8\% for current and $79.9 \%$ for past e-cigarette users). Past experimentation was the most prevalent pattern of e-cigarette use for the whole population of ever e-cigarette users $\left(\chi^{2}=142.5, P<0.001\right)$. Nicotine use was reported by the majority of ever ecigarette users and was more prevalent in current (88.9\%) and past e-cigarette users (84.0\%) compared to past experimenters $\left(68.6 \% ; X^{2}=61.8, P<0.001\right)$. Extrapolated to the total population of 3.1 million adult inhabitants in Attica, there were 1 million current smokers, 848,000 ever e-cigarette users and 155,000 current e-cigarette users at the time of the survey.

\section{E-cigarette use according to the smoking status}

The prevalence of e-cigarette use according to the smoking status is shown in Table 2, including data on daily use and nicotine-containing e-cigarette use. From the total population of ever e-cigarette users, $64.8 \%$ were current smokers, $26.2 \%$ were former smokers and $9.0 \%$ were never smokers. From the total population of current e-cigarette users, $36.3 \%$ were current smokers, $62.2 \%$ were former smokers and $1.5 \%$ were never smokers. 
Table 1 Smoking and e-cigarette use in the total sample

\begin{tabular}{|c|c|c|}
\hline Characteristic & $N$ (unweighted) & $\%(95 \% \mathrm{Cl})$ (weighted) \\
\hline \multicolumn{3}{|l|}{ Smoking } \\
\hline Current smokers & 1281 & $32.6 \%(31.2-34.0 \%)$ \\
\hline Former smokers & 1287 & $29.7 \%(28.3-31.1 \%)$ \\
\hline Never smokers & 1490 & $37.7 \%(36.2-39.2 \%)$ \\
\hline \multicolumn{3}{|l|}{ Smoking frequency ${ }^{1}$} \\
\hline Daily smokers & 2136 & $81.6 \%(80.1-83.1 \%)$ \\
\hline Occasional smokers & 432 & $18.4 \%(16.9-19.9 \%)$ \\
\hline \multicolumn{3}{|l|}{ E-cigarette awareness } \\
\hline Yes & 3642 & $91.7 \%(90.9-92.5 \%)$ \\
\hline No & 407 & $8.1 \%(7.3-8.9 \%)$ \\
\hline \multicolumn{3}{|l|}{ E-cigarette use } \\
\hline Ever use & 924 & $27.2 \%(25.8-28.6 \%)$ \\
\hline Current use & 169 & $5.0 \%(4.3-5.7 \%)$ \\
\hline Past use & 374 & $9.8 \%(8.9-10.7 \%)$ \\
\hline Past experimentation & 381 & $12.4 \%(11.4-13.4 \%)$ \\
\hline Never use ${ }^{2}$ & 3124 & $72.7 \%(71.3-74.1 \%)$ \\
\hline \multicolumn{3}{|l|}{ Frequency of e-cigarette use ${ }^{3}$} \\
\hline Daily use & 435 & $79.5 \%(76.6-82.7 \%)$ \\
\hline Occasional use & 106 & $20.2 \%(17.0-23.4 \%)$ \\
\hline Nicotine-containing e-cigarette use ${ }^{4}$ & 720 & $77.9 \%(75.5-80.3 \%)$ \\
\hline
\end{tabular}

${ }^{1}$ Proportion of current and former smokers

${ }^{2}$ Includes participants who are not aware of e-cigarettes

${ }^{3}$ Proportion of current and past e-cigarette users

${ }^{4}$ Proportion of ever e-cigarette users

Among ever e-cigarette users who were current smokers, past experimentation and past e-cigarette use were more prevalent compared to current e-cigarette use $\left(\chi^{2}=197.2, P<0.001\right)$. Among ever e-cigarette users who were former smokers, current e-cigarette use was more prevalent than former e-cigarette use and past ecigarette experimentation $\left(\chi^{2}=15.1, P=0.001\right)$. Among ever e-cigarette users who were never smokers, past ecigarette experimentation was by far the most prevalent pattern of use $\left(\chi^{2}=178.6, P<0.001\right)$. Characteristically, $92.9 \%$ of never smoking ever e-cigarette users reported past experimentation only. The majority of current and former smokers reported daily current and past ecigarette use. For never smokers, all current and past ecigarette users reported daily use but the overall prevalence of e-cigarette use was very low in this population subgroup.

Similar patterns of use were observed for nicotinecontaining e-cigarettes, with approximately 90\% of current e-cigarette users who reported being current or former smokers were using nicotine. However, such use was very rare among never smokers. Only 1 neversmoking participant reported being current, and 2 reported being former nicotine containing e-cigarette users.

\section{Perception of e-cigarette harmfulness}

The perception of e-cigarette harmfulness for the whole population and according to the smoking status is presented in Table 3. The most prevalent perceptions were that e-cigarettes are equally or less harmful than tobacco cigarettes. A remarkably low proportion perceived ecigarettes as a lot less harmful than cigarettes, including among current smokers, and a substantial proportion responded that they did not know. While no statistically significant differences were observed in the perceptions that e-cigarettes are a lot more or more harmful than smoking, a larger proportion of never smokers considered e-cigarettes less harmful than smoking.

Table 2 E-cigarette use according to the smoking status

\begin{tabular}{|c|c|c|c|}
\hline & \multicolumn{3}{|l|}{ Smoking status } \\
\hline & Current smokers & Former smokers & Never smokers \\
\hline & \multicolumn{3}{|l|}{$\%(95 \%$ Cl) (weighted) } \\
\hline \multicolumn{4}{|l|}{ E-cigarette use } \\
\hline Current use & $5.5 \%(4.3-6.7 \%)$ & $10.4 \%(8.7-12.1 \%)$ & $0.2 \%(0.0-0.4 \%)$ \\
\hline Daily use & $3.0 \%(2.0-3.9 \%)$ & $9.7 \%(8.0-11.3 \%)$ & $0.2 \%(0.0-0.4 \%)$ \\
\hline Past use & $24.0 \%(21.7-26.3 \%)$ & $6.5 \%(5.1-7.9 \%)$ & $0.3 \%(0.0-0.6 \%)$ \\
\hline Daily use & $19.5 \%(17.4-21.7 \%)$ & $5.0 \%(3.8-6.2 \%)$ & $0.3 \%(0.0-0.6 \%)$ \\
\hline Past experimentation & $24.6 \%(22.3-26.9 \%)$ & $7.2 \%(5.7-8.7 \%)$ & $6.0 \%(4.8-7.2 \%)$ \\
\hline Total & $54.1 \%(51.4-56.8 \%)$ & $24.1 \%(21.7-26.5 \%)$ & $6.5 \%(5.3-7.7 \%)$ \\
\hline \multicolumn{4}{|c|}{ Nicotine-containing e-cigarette use } \\
\hline Current use & $5.0 \%(3.8-6.2 \%)$ & $9.4 \%(7.7-11.1 \%)$ & $0.0 \%(0.0-0.0 \%)$ \\
\hline Past use & $20.9 \%(18.7-23.1 \%)$ & $4.7 \%(3.5-5.9 \%)$ & $0.1 \%(0.0-0.2 \%)$ \\
\hline Past experimentation & $18.9 \%(16.8-21.0 \%)$ & $4.4 \%(3.2-5.6 \%)$ & $2.7 \%(1.9-3.5)$ \\
\hline Total & $44.8 \%(42.1-47.5 \%)$ & $18.6 \%(16.4-20.8 \%)$ & $2.9 \%(2.1-3.7 \%)$ \\
\hline
\end{tabular}


Table 3 Perception of e-cigarette harmfulness

\begin{tabular}{llllll}
\hline & $\begin{array}{l}\text { Current smokers } \\
\%(95 \% \mathrm{Cl}) \text { (weighted) }\end{array}$ & Former smokers & Never smokers & Total & $P^{1}$ \\
\hline Perception & & & & & \\
A lot more harmful than smoking & $3.1 \%(2.2-4.0 \%)$ & $2.6 \%(1.7-3.5 \%)$ & $1.9 \%(1.2-2.6 \%)$ & $2.5 \%(2.0-3.0 \%)$ & 0.180 \\
More harmful than smoking & $7.8 \%(6.3-9.2 \%)$ & $6.1 \%(4.7-7.5 \%)$ & $5.4 \%(4.3-6.5 \%)$ & $6.4 \%(5.6-7.2 \%)$ & 0.074 \\
Equally harmful to smoking & $28.6 \%(26.2-31.0 \%)$ & $21.2 \%(18.9-23.5 \%)$ & $26.3 \%(24.1-28.5 \%)$ & $25.5 \%(24.2-26.8 \%)$ & 0.005 \\
Less harmful than smoking & $30.9 \%(28.4-33.4 \%)$ & $30.0 \%(27.4-32.6 \%)$ & $36.3 \%(33.9-38.7 \%)$ & $32.7 \%(31.3-34.1 \%)$ & $<0.001$ \\
A lot less harmful than smoking & $4.6 \%(3.5-5.7 \%)$ & $6.8 \%(5.4-8.2 \%)$ & $5.0 \%(3.9-6.1 \%)$ & $5.4 \%(4.7-6.1 \%)$ & 0.008 \\
Absolutely harmless & $0.7 \%(0.3-1.1 \%)$ & $2.7 \%(1.8-3.6 \%)$ & $1.0 \%(0.5-1.5 \%)$ & $1.4 \%(1.0-1.8 \%)$ & $<0.001$ \\
Don't know & $20.5 \%(18.3-22.7 \%)$ & $18.8 \%(16.6-21.0 \%)$ & $14.7 \%(12.9-16.5 \%)$ & $17.8 \%(16.6-19.0 \%)$ & 0.001 \\
\hline
\end{tabular}

${ }^{1}$ Comparison between current, former and never smokers $\left(x^{2}\right.$ test)

Additionally, more former smokers considered ecigarettes a lot less harmful than smoking or absolutely harmless and more current smokers were uncertain about the harmfulness of e-cigarettes.

\section{Correlates of current and ever e-cigarette use}

The results of the logistic regression analyses are presented in Table 4. Being current or former smoker were the strongest correlates of ever e-cigarette use. Age younger than 55, male gender and perception of low harm for e-cigarettes were also correlates of ever ecigarette use. University education and being married/ living with partner were negatively associated with ever e-cigarette use.

For current e-cigarette use, being current or former smoker were also by far the strongest correlates. Age 25-39 years, male gender and perception of low harm for e-cigarettes were also correlates of current ecigarette use. University education was negatively associated with current e-cigarette use.

\section{Discussion}

This study presents the first evidence on prevalence and patterns of e-cigarette use in Greece, a European country with a very high prevalence of smoking. The study identified almost universal awareness of e-cigarettes, while more than 1 out of 4 participants reported ever ecigarette use. However, current e-cigarette use was substantially lower and mainly confined to current and former smokers, with the latter representing the majority of current e-cigarette users.

The prevalence of current e-cigarette use in Greece is similar to the UK, where it was recently reported that 5 . $8 \%$ of the population is using e-cigarettes [25]. In the EU in 2014, current e-cigarette use was reported by $1.8 \%$ of the population, with $60 \%$ of current users reporting daily use $[24,26]$. In the United States (US) in 2014, the prevalence of current e-cigarette use (defined as any past 30 -day use) was $5.5 \%$, with only $21.3 \%$ of those reporting daily use. These data identify higher prevalence and more intense use by the Greek population compared to the average use in the EU and the US while use prevalence is similar compared to the UK, a country with a positive environment for e-cigarettes among the public health community. There has been a lot of debate about the definition of current e-cigarette use in the US, defined as any past 30-day use, because it includes a lot of recent experimenters [27]. Additionally, frequency of e-cigarette use is positively associated with both quit attempts and quit success [28]. Considering that frequency of use seems to vary considerably between different populations, it is important to record such information in population surveys in order to make proper comparisons. Frequency of use and nicotine use are among the principle items that are recommended as measures included in population surveys examining e-cigarette use [29].

An important finding of this study is the high proportion of current e-cigarette users who were former smokers. Being current and former smoker were the strongest correlates of e-cigarette use, with a particularly strong association observed for former smokers. Ecigarettes were also by far the most popular smoking cessation aid among current daily smokers. Similar findings have been observed in the UK where the proportion of e-cigarette users being former smokers surpassed current smokers for the first time in 2017 [25] while, over the past 3 years, e-cigarettes have replaced nicotine replacement therapies as the most popular alternative to smoking for people trying to quit [30]. Current ecigarette use was remarkably uncommon among Greek never smokers. These findings provide indirect evidence that e-cigarette use is maintained because it helps smokers quit, while e-cigarettes are not attractive to never smokers. This represents a desirable effect from a public health perspective and appears reassuring for the potential threat that e-cigarettes act as a gateway to smoking. However, there are inherent limitations in 
Table 4 Correlates of ever and current e-cigarette use

\begin{tabular}{|c|c|c|c|c|}
\hline \multirow[b]{2}{*}{ Correlates } & \multicolumn{2}{|l|}{ Ever e-cigarette use } & \multicolumn{2}{|l|}{ Current e-cigarette use } \\
\hline & OR $(95 \% \mathrm{Cl})$ & $P$ & OR $(95 \% \mathrm{Cl})$ & $P$ \\
\hline \multicolumn{5}{|l|}{ Smoking status } \\
\hline \multicolumn{5}{|l|}{ Never smokers (referent) } \\
\hline Current smokers & $33.38(25.20-44.21)$ & $<0.001$ & $30.82(10.21-93.01)$ & $<0.001$ \\
\hline Ex-smokers & $9.05(6.81-12.04)$ & $<0.001$ & $69.33(23.12-207.90)$ & $<0.001$ \\
\hline \multicolumn{5}{|l|}{ Age (years) } \\
\hline \multicolumn{5}{|l|}{55 and older (referent) } \\
\hline $18-24$ & $5.74(3.82-8.63)$ & $<0.001$ & $1.83(0.89-3.80)$ & 0.103 \\
\hline $25-39$ & $3.50(2.68-4.59)$ & $<0.001$ & $2.50(1.57-4.0)$ & $<0.001$ \\
\hline $40-54$ & $1.68(1.33-2.13)$ & $<0.001$ & $1.19(0.77-1.84)$ & 0.444 \\
\hline \multicolumn{5}{|l|}{ Gender } \\
\hline \multicolumn{5}{|l|}{ Female (referent) } \\
\hline Male & $1.22(1.02-1.45)$ & 0.029 & $1.46(1.06-2.01)$ & 0.020 \\
\hline \multicolumn{5}{|l|}{ Education } \\
\hline \multicolumn{5}{|l|}{ High school or less (referent) } \\
\hline Technical education & $0.93(0.69-1.27)$ & 0.664 & $0.92(0.56-1.53)$ & 0.754 \\
\hline University education & $0.71(0.58-0.88)$ & 0.001 & $0.53(0.37-0.77)$ & 0.001 \\
\hline Postgraduate education & $0.82(0.60-1.13)$ & 0.226 & $0.61(0.35-1.06)$ & 0.079 \\
\hline \multicolumn{5}{|l|}{ Marital status } \\
\hline \multicolumn{5}{|l|}{ Single (referent) } \\
\hline Married/living with partner & $0.70(0.56-0.89)$ & 0.003 & $0.98(0.65-1.47)$ & 0.910 \\
\hline Divorced, widowed or other & $0.86(0.60-1.25)$ & 0.432 & $1.54(0.80-2.95)$ & 0.196 \\
\hline \multicolumn{5}{|l|}{ Financial situation } \\
\hline \multicolumn{5}{|l|}{ Very bad/bad (referent) } \\
\hline Not good & $0.99(0.82-1.21)$ & 0.950 & $0.75(0.53-1.06)$ & 0.101 \\
\hline Good & $1.30(0.97-1.74)$ & 0.075 & $1.02(0.62-1.67)$ & 0.947 \\
\hline \multicolumn{5}{|l|}{ Perceived of e-cigarette harmfulness } \\
\hline \multicolumn{5}{|c|}{ A lot more harmful/more harmful/equally harmful/DK (referent) } \\
\hline Less harmful/a lot less harmful/harmless & $2.81(2.34-3.37)$ & $<0.001$ & $6.28(4.35-9.07)$ & $<0.001$ \\
\hline
\end{tabular}

cross-sectional surveys when addressing such research questions, which are discussed below.

An important issue raised by the study herein is the overestimation of e-cigarette harmfulness relative to smoking. Only about 1 in 20 participants correctly considered e-cigarettes as a lot less harmful than smoking while perceptions of low harmfulness was a correlate of ever and current e-cigarette use. Such misconceptions were more pronounced among smokers. Several studies have shown a growing misconception in the general population about the relative risks of e-cigarettes [25, 31-33]. Brose et al. found that perception of low harm predicted subsequent use of e-cigarettes in a cohort of current and former smokers [31]. A cross-sectional survey of dedicated vapers found that perception of low harm was independently associated with being exclusive e-cigarette user rather than dual user [34]. Since overestimating their harmfulness may discourage smokers from using e-cigarettes in an effort to quit smoking, there is a need to provide accurately and reliable information about the risks of smoking and ecigarette use, particularly to smokers [19, 35]. Studies need to examine the factors associated with such misconceptions. For example, media articles that largely exaggerate the potential adverse health effects of ecigarettes and provide no comparison with the effects of smoking, a phenomenon that is frequently observed in Greece, could be responsible for providing misleading messages to smokers [19].

Limitations applicable to this study are the inherent weaknesses of cross-sectional studies. Associations cannot be interpreted as causation, while lack of temporality does not allow for determining if e-cigarette use preceded smoking cessation in former smokers. The 
smoking status was self-reported and not objectively verified, which is common for large population studies. Still, the study is valuable in showing for the first time that e-cigarette use in the Greek population is adopted by smokers only and is minimal among never smokers, largely rejecting the concerns about gateway to smoking effects.

\section{Conclusions}

In conclusion, current e-cigarette use in Greece is predominantly confined among current and former smokers. In never smokers, minimal experimentation and almost no current use was observed. The majority of current e-cigarette users reported being former smokers, while e-cigarettes are the most popular smoking cessation aid among current daily smokers over the past 3 years. The findings suggest a positive public health impact of e-cigarettes in Greece, which is particularly important for a country having a high prevalence of smoking, and provide reassurance that e-cigarettes are not popular among never smokers. However, major misconceptions about the relative risks of e-cigarettes compared to smoking exist in the population, and this needs to be addressed.

\section{Additional file}

Additional file 1: Table S1. Demographics of study participants. (DOCX $14 \mathrm{~kb}$ )

\section{Abbreviations}

EU: European Union; US: United States

\section{Availability of data and materials}

The datasets analysed during the current study are available from the corresponding author on reasonable request.

\section{Authors' contributions}

KF conceived of the study. KF, GS, KM and AB developed the questionnaire. GS was responsible for performing the telephone survey. KF, KP and W performed the statistical analysis. KP, W, KM and $A B$ helped to draft the manuscript. All authors read and approved the final manuscript.

\section{Ethics approval and consent to participate}

The study was approved by the ethics committee of Onassis Cardiac Surgery Center, and verbal informed consent was provided by all participants during the telephone survey.

\section{Competing interests}

In the past 36 months, two studies by KF were performed using unrestricted funds by the non-profit association AEMSA and one study was funded by the non-profit association Tennessee Smoke-Free Association. The other authors declare that they have no competing interests.

\section{Publisher's Note}

Springer Nature remains neutral with regard to jurisdictional claims in published maps and institutional affiliations.

\section{Author details}

'Onassis Cardiac Surgery Center, Sygrou 356, 17674 Kallithea, Greece. ${ }^{2}$ Department of Pharmacy, University of Patras, 26500 Rio, Greece. ${ }^{3}$ National School of Public Health, Alexandras Av. 196, 11521 Athens, Greece. ${ }^{4}$ Public
Opinion Research Unit, University of Macedonia, Egnatia 156, 54636 Thessaloniki, Greece.

Received: 19 March 2018 Accepted: 2 April 2018

Published online: 13 April 2018

\section{References}

1. Farsalinos KE, Polosa R. Safety evaluation and risk assessment of electronic cigarettes as tobacco cigarette substitutes: a systematic review. Ther Adv Drug Saf. 2014;5:67-86.

2. Hajek P, Etter JF, Benowitz N, Eissenberg T, McRobbie H. Electronic cigarettes: review of use, content, safety, effects on smokers and potential for harm and benefit. Addiction. 2014;109:1801-10.

3. Glasser AM, Collins L, Pearson $\mathrm{L}$, Abudayyeh H, Niaura RS, Abrams DB, Villanti AC. Overview of electronic nicotine delivery systems: a systematic review. Am J Prev Med. 2017;52:e33-66.

4. Farsalinos K. Electronic cigarettes: an aid in smoking cessation, or a new health hazard? Ther Adv Respir Dis. 2018;12:1753465817744960.

5. Caponnetto P, Campagna D, Cibella F, Morjaria JB, Caruso M, Russo C, et al. Efficiency and Safety of an eLectronic cigAreTte (ECLAT) as tobacco cigarettes substitute: a prospective 12-month randomized control design study. PLoS One. 2013:8:e66317.

6. Bullen C, Howe C, Laugesen M, McRobbie H, Parag V, Williman J, et al. Electronic cigarettes for smoking cessation: a randomised controlled trial. Lancet. 2013;382:1629-37.

7. Adriaens K, Van Gucht D, Declerck P, Baeyens F. Effectiveness of the electronic cigarette: an eight-week Flemish study with six-month follow-up on smoking reduction, craving and experienced benefits and complaints. Int J Environ Res Public Health. 2014:11:11220-48.

8. Hartmann-Boyce J, McRobbie H, Bullen C, Begh R, Stead LF, Hajek P. Electronic cigarettes for smoking cessation. Cochrane Database Syst Rev. 2016:9:CD010216.

9. Brose LS, Hitchman SC, Brown J, West R, McNeill A. Is the use of electronic cigarettes while smoking associated with smoking cessation attempts, cessation and reduced cigarette consumption? A survey with a 1-year follow-up. Addiction. 2015;110:1160-8.

10. Al-Delaimy WK, Myers MG, Leas EC, Strong DR, Hofstetter CR. E-cigarette use in the past and quitting behavior in the future: a population-based study. Am J Public Health. 2015;105:1213-9.

11. Biener L, Hargraves JL. A longitudinal study of electronic cigarette use among a population-based sample of adult smokers: association with smoking cessation and motivation to quit. Nicotine Tob Res. 2015:17:127-33.

12. Vickerman KA, Carpenter KM, Altman T, et al. Use of electronic cigarettes among state tobacco cessation quitline callers. Nicotine Tob Res. 2013;15: 1787-93.

13. Rahman MA, Hann N, Wilson A, Mnatzaganian G, Worrall-Carter L. Ecigarettes and smoking cessation: evidence from a systematic review and meta-analysis. PLoS One. 2015;10:e0122544.

14. Kalkhoran S, Glantz SA. E-cigarettes and smoking cessation in real-world and clinical settings: a systematic review and meta-analysis. Lancet Respir Med. 2016:4:116-28.

15. El Dib R, Suzumura EA, Akl EA, et al. Electronic nicotine delivery systems and/or electronic non-nicotine delivery systems for tobacco smoking cessation or reduction: a systematic review and meta-analysis. BMJ Open. 2017;7:e012680

16. Villanti AC, Feirman SP, Niaura RS, Pearson JL, Glasser AM, Collins LK, Abrams DB. How do we determine the impact of e-cigarettes on cigarette smoking cessation or reduction? Review and recommendations for answering the research question with scientific rigor. Addiction. 2018:113:391-404.

17. Frieden TR. Evidence for health decision making - beyond randomized. Controlled Trials N Engl J Med. 2017;377:465-75.

18. Beard E, West R, Michie S, Brown J. Association between electronic cigarette use and changes in quit attempts, success of quit attempts, use of smoking cessation pharmacotherapy, and use of stop smoking services in England: time series analysis of population trends. BMJ. 2016;354:14645.

19. McNeill A, Brose LS, Calder R, Bauld L, Robson D. Evidence review of ecigarettes and heated tobacco products 2018. A report commissioned by Public Health England. 2018. Available at: https://www.gov.uk/ government/publications/e-cigarettes-and-heated-tobacco-productsevidence-review/evidence-review-of-e-cigarettes-and-heated-tobaccoproducts-2018-executive-summary (accessed on 15 Feb 2018). 
20. European Commission. Eurobarometer 429. Attitudes of Europeans towards tobacco and electronic cigarettes. 2014. Available at: http://ec.europa.eu/ public_opinion/archives/ebs/ebs_429_en.pdf (accessed 13 Jan 2018).

21. European Commission. Special Eurobarometer 183. Smoking and the environment: actions and attitudes. 2003. Available at: http://ec.europa.eu/ health/ph_determinants/life_style/Tobacco/Documents/eb582_smoking_ env_en.pdf (accessed 26 Mar 2018).

22. Groves RM, Fowler FJ, Couper MP, Lepkowski JM, Singer E, Tourangeau R. Survey methodology. 2nd ed. Hoboken: Wiley; 2009. ISBN: 978-0-470-46546-2

23. Donsbach W, Traugott MW, editors. Handbook of public opinion research. Thousand Oaks: SAGE. ISBN: 978-1-4129-1177-1; 2008. https://doi.org/10. 4135/9781848607910.

24. Farsalinos KE, Poulas K, Voudris V, Le Houezec J. Electronic cigarette use in the European Union: analysis of a representative sample of 27460 Europeans from 28 countries. Addiction. 2016;111:2032-2040. https://doi. org/10.1111/add.13506.

25. Action on Smoking and Health (ASH) UK. Use of electronic cigarettes (vapourisers) among adults in Great Britain. 2017. Available at: ash.org.uk/ information-and-resources/fact-sheets/use-of-e-cigarettes-among-adults-ingreat-britain-2017/ (Accessed 3 Aug 2017).

26. Farsalinos KE, Poulas K, Voudris V, Le Houezec J. Prevalence and correlates of current daily use of electronic cigarettes in the European Union: analysis of the 2014 Eurobarometer survey. Intern Emerg Med. 2017; https://doi.org/ 10.1007/s11739-017-1643-1647.

27. Amato MS, Boyle RG, Levy D. How to define e-cigarette prevalence? Finding clues in the use frequency distribution. Tob Control. 2016:25:e24-9.

28. Levy DT, Yuan Z, Luo Y, Abrams DB. The relationship of E-cigarette use to cigarette quit attempts and cessation: insights from a large, nationally representative U.S. survey. Nicotine Tob Res. 2017; https://doi.org/10.1093/ $\mathrm{ntr} / \mathrm{ntx} 166$.

29. Pearson JL, Hitchman SC, Brose LS, Bauld L, Glasser AM, Villanti AC, McNeill A, Abrams DB, Cohen JE. Recommended core items to assess e-cigarette use in population-based surveys. Tob Control. 2017. https://doi.org/10.1136/ tobaccocontrol-2016-053541.

30. Brown J, West R, Beard E, Michie S, Shahab L, McNeill A. Prevalence and characteristics of e-cigarette users in Great Britain: findings from a general population survey of smokers. Addict Behav. 2014;39:1120-5.

31. Brose LS, Brown J, Hitchman SC, MCNeill A. Perceived relative harm of electronic cigarettes over time and impact on subsequent use. A survey with 1-year and 2-year follow-ups. Drug Alcohol Depend. 2015;157:106-11.

32. Tan AS, Bigman CA. E-cigarette awareness and perceived harmfulness: prevalence and associations with smoking-cessation outcomes. Am J Prev Med. 2014;47:141-9.

33. Majeed BA, Weaver SR, Gregory KR, Whitney CF, Slovic P, Pechacek TF, Eriksen MP. Changing perceptions of harm of E-cigarettes among U.S. adults, 2012-2015. Am J Prev Med. 2017;52:331-8.

34. Farsalinos $K E$, Romagna $G$, Voudris V. Factors associated with dual use of tobacco and electronic cigarettes: a case control study. Int J Drug Policy. 2015;26:595-600

35. Kozlowski LT, Sweanor DT. Do not damn tobacco users to ignorance about big differences in deadly products because you disapprove of the 'bus' they are on. Addict Behav. 2018;77:287-8.

\section{Ready to submit your research? Choose BMC and benefit from:}

- fast, convenient online submission

- thorough peer review by experienced researchers in your field

- rapid publication on acceptance

- support for research data, including large and complex data types

- gold Open Access which fosters wider collaboration and increased citations

- maximum visibility for your research: over $100 \mathrm{M}$ website views per year

At BMC, research is always in progress.

Learn more biomedcentral.com/submissions 